\section{Cancer money siphoned off to pay debts}

Owen Dyer London and
Bryan Christie Edinburgh

Money promised to improve cancer care has been "purloined" by NHS trusts to pay their debts, according to a report by the Commons Select Committee on Science and Technology.

About half of the sum delivered as part of the government's cancer plan-£280m (\$400m; $€ 450)$ of $£ 570 \mathrm{~m}$-has disappeared into the health service without any noticeable benefit to patients, said the MPs.

The committee also questioned whether the government has kept its promise to match charitable spending on cancer research, dismissing as creative accounting the health department's claim to be spending $£ 190 \mathrm{~m}$ annually on research.

Ian Gibson, Labour MP for Norwich North and the committee's chairman, said the department had reached this figure by "rebadging" money already spent on cancer treatment or on research only distantly related to cancer.

The committee's report concludes: "We are not convinced that the $£ 190$ million which the government claims to be spend- ing on cancer research is being spent on cancer research alone."

The committee heard evidence from various cancer research organisations, as well as the national cancer director, Professor Mike Richards, who admitted having heard reports that some of the money provided under the cancer plan could have been spent on other things.

"The arrangement for next year is much stronger," he told the committee.

In a statement issued later he said: "Ultimately it is up to the local NHS to decide how best to spend extra NHS investment But we have made it very clear that this was allocated to health authorities to improve cancer services, and that is what we expect to see happen. They will need to account for this investment at the end of this financial year."

The committee's report concluded: "We are seriously concerned at the apparent ease with which trusts can redeploy such funds if they choose. We consider it dissembling to allocate funding to cancer care, with great publicity, without taking even the simplest precaution to ensure it reaches the intended areas."

The MPs said their task of tracking the missing money had been made harder by "the attitude of the Department of Health to the provision of financial facts and figures," which they described as "highly frustrating."

- Women in Scotland with

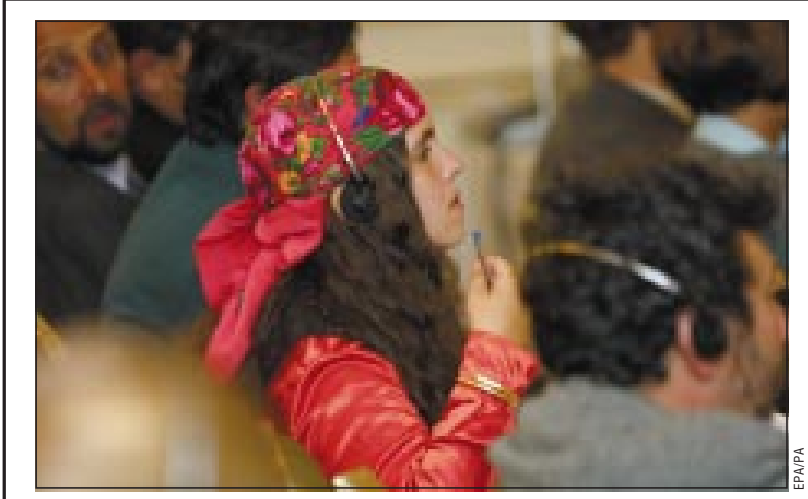

A government survey has found that the overall health of Hungary's Roma (Gypsies) is much worse than that of the average population.

A health ministry report based on the survey said the average life expectancy of the country's Roma is 10 to 15 years lower than that of the non-Roma population and cites unemployment, poor nutrition, substandard housing, environmental pollution, and workplace hazards as major contributing factors. The life expectancy of the general population is 71 years.

The report stated that most Roma have unhealthy eating habits, consuming cheap foods rich in fat and carbohydrates.

Malnutrition and hunger are acute problems.

Carl Kovac Budapest

breast and ovarian cancer are waiting "unacceptably long" for certain treatments, says the first review of cancer services carried out by the Clinical Standards Board for Scotland.

No Scottish hospital was able to offer radiotherapy for breast cancer within the recommended period of four weeks after surgery, and concern was also expressed about delays in delivering chemotherapy.

The reports on breast and ovarian cancer found that the number of women in Scotland getting the best evidence based treatments is increasing.

The Clinical Standard Board's reports are available at www.clinicalstandards.org

\section{New test simplifies genetic testing for breast cancer}

\author{
Xavier Bosch Barcelona
}

Mortality associated with breast cancer has decreased by $25 \%$ over the past decade, Josep Baselga, head of the oncology unit of the Hospital Vall d'Hebrón in Barcelona, told the third European breast cancer conference last week.

In addition to the introduction of new drugs, a leading cause for such reduction was the progressive expansion of screening programmes, he told delegates at the conference in Barcelona, attended by more than 4000 specialists.

The conference also heard from the United Kingdom's Nottingham Research Unit about a new test to detect genetic mutations in hereditary breast cancer that seems to be easier and more cost effective than current ones based on blood analysis, while maintaining a high accuracy.

Dr José Antonio Cid, the principal investigator of the study, said that the only requirement was to find archival tissue samples from tumours affecting two relatives with a previous diagnosis of breast cancer, which he said was "something not too hard in British hospitals, where samples are well registered."

The team recruited 67 family pairs (sister/sister; mother/ daughter; aunt/niece) at high risk of developing hereditary breast cancer from the strength of their family history. The team was not aware whether the women had mutations in the breast cancer genes BRCA1 and BRCA2.

The team analysed samples from two tumours per family to see whether there was a loss of genetic material close to the BRCA genes and whether the same loss was seen in the same place in both tumour samples. Most of the families had tumours in two relatives, and 14 had two tumours in one person-either in both breasts or breast plus ovary.

The researchers speculated that if the same loss of heterozygosity was detected in the same place in two different tumours in a family it could point to an underlying hereditary mutation in a breast cancer gene.

Dr Cid chose five spots or "microsatellite markers" close to the BRCA1 and BRCA2 genes to search for loss of heterozygosity. Then he matched the results from these tests with the results from standard genetic mutational analysis performed in blood samples from the same individuals. He found that in $50 \%(4 / 8)$ of cases where loss of heterozygosity predicted a mutation in BRCA1 or BRCA2, this was confirmed by mutation analysis.

Gene testing for high risk people currently requires a full mutational analysis that has been done first in the blood of a living, affected relative. Dr Cid said: "This is time consuming and expensive. Our alternative procedure also requires analysis in relatives, but this can be done in tissue stored from an operation sometimes carried out many years ago, and it is quick, easy, and affordable." 